\title{
Anesthesia considerations for robotic surgery in gynecologic oncology
}

\author{
Mohamed Badawy $\cdot$ François Béïque $\cdot$ Hani Al-Halal $\cdot$ \\ Tania Azar $\cdot$ Khalid Akkour • Susie K. Lau • \\ Walter H. Gotlieb
}

Received: 15 January 2011 / Accepted: 26 February 2011 / Published online: 25 March 2011

(C) Springer-Verlag London Ltd 2011

\begin{abstract}
Robot-assisted gynecologic surgery is performed with a pneumoperitoneum and prolonged maximum Trendelenburg position which can result in adverse physiologic effects. The purpose of this study was to assess the feasibility of robot-assisted gynecologic oncology procedures and to identify anesthesia-related peri-operative adverse events. This is a case series performed on the first 133 patients who underwent a robot-assisted gynecologic oncology procedure at a tertiary care facility. Data was collected from electronically archived patient charts and from a prospective surgical database. Patient demographics were recorded and significant intra-operative and post-operative adverse events were reviewed. Robot-assisted surgery for gynecologic oncologic surgery with the use of extreme Trendelenburg in all patients was safely and successfully performed across a wide range of ages, American Society of Anesthesiologists physical status scores and body mass indices. Although most patients developed various degree of facial edema, only $5 \%$ of patients had a delayed extubation. Transient intra-operative hypoxemia $\left(\mathrm{O}_{2}\right.$ saturation $\left.<90 \%\right)$ occurred in $3.75 \%(5 / 133)$ of patients and hypercapnia $\left(\mathrm{CO}_{2}>45 \mathrm{mmHg}\right)$ in $18 \%(24 / 133)$. The mean duration of surgery was 254 min and median hospital stay was 1 day. Anesthetic and peri-operative complications are rare for patients undergoing robot-assisted gynecologic oncology surgeries despite the prolonged use of maximum
\end{abstract}

\footnotetext{
M. Badawy · F. Béique ( $\square)$

Department of Anesthesia, SMBD Jewish General Hospital, McGill University, 3755 Côte Ste. Catherine Road,

Montreal, QC H3T 1E2, Canada

e-mail: fbeique@ana.jgh.mcgill.ca

H. Al-Halal · T. Azar · K. Akkour · S. K. Lau · W. H. Gotlieb Division of Gynecologic Oncology, Segal Cancer Center, SMBD Jewish General Hospital, McGill University,

3755 Côte Ste. Catherine Road, Montreal, QC H3T 1E2, Canada
}

Trendelenburg positioning and pneumoperitoneum. Although there are new anesthetic challenges, these surgeries were safely performed in a wide range of patients with minimal blood loss, short hospital stay and no significant cardiopulmonary complications.

Keywords Anesthesia - Safety · Gynecologic oncology · Endometrial cancer $\cdot$ Cervix cancer $\cdot$ Robot-assisted surgery

\section{Introduction}

The da Vinci Surgical System (Intuitive Surgical, Sunnyvale, CA, USA) was first introduced into medical practice in 1999 and was approved by the US Food and Drug Administration for use in gynecology in 2005. The robot does not replace the surgeon but rather "teleports" the latter to the operating site and enables operation on the patient from an ergonomic console using three-dimensional vision and autonomous control of wristed laparoscopic surgical instruments [1]. A more accurate and encompassing term for this device is a "computer-enhanced telemanipulator" [2]. This new system improves precision and enhances accuracy of the movements, translating into numerous potential patient benefits. [3, 4].

Robotics in gynecologic oncology has distinctive features that set it apart from traditional laparoscopy. In addition to the adverse physiologic effect of a pneumoperitoneum, patient positioning in $30^{\circ}$ Trendelenburg (maximum) without change throughout the procedure, in view of the docking of the robot, could lead to upper airway and brain edema, as well as respiratory and hemodynamic compromise. Unnoticed injury, occult blood loss, risk of hypothermia, limited access to the patient and inability to 
rapidly modify patient positioning after docking of the robotic arms also complicate the anesthetic care. Moreover, it is unclear if this procedure can be well tolerated in obese and elderly patients [2].

The purpose of this study is to establish feasibility of robot-assisted surgery in gynecologic oncology and to identify surgical and anesthesia-related peri-operative complications by performing a quality assurance retrospective study based on the first group of patients operated on at our institution using the da Vinci robotic system in gynecologic oncology.

\section{Materials and methods}

The hospital institutional review board approved this study on robot-assisted surgery in gynecologic oncology patients. Since the inauguration of the robotics programs in December 2007 until June 2009, two gynecologic oncologists (SKL and WHG) have used the da Vinci System to perform 133 surgeries, which were included in this series. The clinical database was established prospectively and included patient characteristics, surgical indications and procedures, surgical times, intra-operative complications, post-operative complications and hospital length of stay. An electronic charting system was also used to assess anesthesia-related complications, cardiopulmonary adverse effects, post-operative nausea and vomiting, hypothermia upon arrival to the Post-Anesthesia Care Unit (PACU), requirements for mechanical ventilation in the PACU and laboratory data.

For robot-assisted gynecological oncology procedures, the patient is placed on an egg crate mattress that is attached to the bed with the lower extremities in padded lithotomy stirrups. The entire upper extremity is wrapped in foam padding and tucked at the patient's side using the bed sheet. Shoulder braces covered with gel foam pads are used as additional safety devices. This helps prevent injury to the brachial plexus and ulnar nerve. All of our patients were monitored with an arterial line. Insufflation pressure was limited to $15 \mathrm{mmHg}$ and muscle relaxation was used to facilitate mechanical ventilation and abdominal distension with insufflated $\mathrm{CO}_{2}$. Surgical bleeding was assessed by the peri-operative decrease in hemoglobin level on the following post-operative day and the requirement for blood transfusion. The effects of extreme $\left(30^{\circ}\right)$ Trendelenburg and pneumoperitoneum (insufflation pressure of $8-15 \mathrm{mmHg}$ of $\left.\mathrm{CO}_{2}\right)$ on the intra-operative occurrence of hypoxemia $\left(\mathrm{O}_{2}\right.$ saturation $<90 \%$ ), hypercarbia (end tidal $\mathrm{CO}_{2}>45 \mathrm{mmHg}$ ), and hypotension (defined as systolic blood pressure $<80 \mathrm{mmHg}$ ) during the surgical procedure were assessed by reviewing the anesthesia records. The anesthetic care of the patients varied according to the anesthesiologist and
Table 1 Patient characteristics

\begin{tabular}{ll}
\hline & Mean \pm SD (min: max) \\
\hline Age (years) & $60.9 \pm 14.1(33: 93)$ \\
Body mass index $\left(\mathrm{kg} / \mathrm{m}^{2}\right)$ & $29.7 \pm 8.1(19.1: 58.8)$ \\
ASA $1,2,3$ (number of patients) & $22,88,23$ \\
Previous abdominal surgery & $57(42.9 \%)$ \\
$\quad$ (number of patients) & Number of patients $(\%)$ \\
Co-morbidities & $53(39.8 \%)$ \\
Hypertension & $15(11.3 \%)$ \\
Diabetes & $25(18.8 \%)$ \\
Cardiovascular disease & $41(37.3 \%)$ \\
Obesity & $5(3.8 \%)$ \\
Asthma & $11(8.3 \%)$ \\
Active smokers & $74(55.6 \%)$ \\
Other co-morbidities & $\mathrm{a}$ \\
\hline
\end{tabular}

ASA American Society of Anesthesiologists physical status score

a "Other co-morbidities" included COPD, obstructive sleep apnea, depression, chronic renal failure, schizophrenia, hypothyroidism, history of cancer (melanoma, breast cancer, esophageal cancer, colon cancer, Hodgkin's lymphoma), fibromyalgia, Alzheimer's disease, cardiac arrhythmias (atrial fibrillation, SVT, Wolff-Parkinson-White syndrome), Crohn's disease, pulmonary embolism, multiple sclerosis, Sjögren's syndrome, bipolar disorder, Cushing's disease, Parkinson's disease, Raynaud's phenomenon and seizure disorder

was administered by one of 18 anesthesiologists on the staff. The mean values and standard deviations were calculated when appropriate.

\section{Results}

Patient characteristics are outlined in Table 1. The ages of the patients we treated were quite varied, ranging from 33 to 93 ; so was their body mass index (BMI), with a range of 19-58.8 (Table 1).

The indication for the surgical procedure was endometrial cancer in 101 patients (75.9\%), ovarian cancer in 14 patients $(10.5 \%)$, cervical cancer in 12 patients $(9 \%)$ and risk-reducing salpingo-oophorectomy in 6 patients $(4.5 \%)$. Eighty-three percent of the surgeries were robot-assisted hysterectomies with unilateral or bilateral salpingo-oophorectomies and lymphadenectomies, $10.5 \%$ were radical hysterectomies, while the remainder included salpingooophorectomies, pelvic mass resections, and omentectomies.

Surgical and anesthesia-related adverse events are presented in Table 2. Brachial plexus injuries associated with the use of shoulder braces have been reported by others [6]. In addition, injury to the sciatic nerve, obturator nerve, peroneal nerve and lateral femoral cutaneous nerve have all been reported in association with robot-assisted procedures 
Table 2 Intra-operative events and complications

\begin{tabular}{|c|c|}
\hline $\begin{array}{l}\text { Estimated blood loss: POD \# } 1 \\
\text { decrease in hemoglobin } \\
\text { concentration }(\mathrm{mg} / \mathrm{dl})\end{array}$ & $21.5 \pm 12.8$ \\
\hline Packed red blood cell transfusion & $1(0.75 \%)$ \\
\hline $\begin{array}{l}\text { Intra-operative hypotension } \\
\quad \text { (systolic } \mathrm{BP}<80 \mathrm{mmHg} \text { ) }\end{array}$ & $3(2.25 \%)$ \\
\hline $\begin{array}{l}\text { Intra-operative hypercapnia } \\
\qquad\left(\text { ET- } \mathrm{CO}_{2}>45 \mathrm{mmHg} \text { during the case }\right)\end{array}$ & $24(18 \%)$ \\
\hline $\begin{array}{l}\text { Intra-operative hypoxemia } \\
\left(\mathrm{O}_{2} \text { saturation }<90 \%\right)\end{array}$ & $5(3.75 \%)$ \\
\hline \multicolumn{2}{|l|}{ Surgical complications } \\
\hline 3-cm bladder laceration-repaired intra-op & $1(0.75 \%)$ \\
\hline $\begin{array}{l}\text { Occult small bowel injury/laceration } \\
\text { with post-op abscess }\end{array}$ & $1(0.75 \%)$ \\
\hline Small bowel serosal tear-repaired intra-op & $1(0.75 \%)$ \\
\hline Vaginal wall laceration-repaired intra-op & $1(0.75 \%)$ \\
\hline $\begin{array}{l}\text { Complications requiring } \\
\text { conversion to laparotomy }\end{array}$ & 0 \\
\hline $\begin{array}{l}\text { Mini-laparotomy for removal } \\
\text { of large uterus }\end{array}$ & $4(3 \%)$ \\
\hline $\begin{array}{l}\text { Technical difficulties with the } \\
\text { robot (robot stopped) }\end{array}$ & $1(0.75 \%)$ \\
\hline
\end{tabular}

$P O D \# 1$ post-operative day $1, E T-C_{2}$ end tidal $\mathrm{CO}_{2}$

and stirrup placement [7]. None of these nerve injuries occurred in any of our patients. Transient hypotension (less than $5 \mathrm{~min}$ ) with a systolic blood pressure less than $80 \mathrm{mmHg}$ occurred in only $2.3 \%$ of patients. Transient hypoxemia with a saturation less than $90 \%$ occurred in $3.8 \%$ of patients while hypercapnea with an end tidal $\mathrm{CO}_{2}$ greater than $45 \mathrm{mmHg}$ occurred in $18 \%$ of patients. At the end of the surgical procedure, 126 patients $(94.7 \%)$ were successfully extubated in the operating room without complication. Only 7 patients $(5.3 \%)$ were not extubated immediately at the end of the surgery and required transient post-operative mechanical ventilation (Table 3). All these patients were extubated within $7 \mathrm{~h}$ and none required admission to the intensive care unit. These patients were on average 6 years older (mean age 67, as compared to 61), and had on average surgeries lasting $1 \mathrm{~h}$ longer (316 min as compared to $254 \mathrm{~min}$ ). Three of them had intra-operative hypothermia and the 4 others had intra-operative hypercapnia, but there was no difference in BMI $\left(28 \mathrm{~kg} / \mathrm{m}^{2}\right.$ compared to 30$)$, American Society of Anesthesiologists physical status scores [2] or hemoglobin levels post-operatively $(110 \mathrm{mg} / \mathrm{dl})$. None had intra-operative hypotension or hypoxia, and none were smokers or suffered from asthma. Possible explanations could therefore include concern about facial edema, hypothermia, hypercapnia, timing of muscle relaxants and/ or reversal, as well as narcotic usage. The mean and standard deviation for the duration of surgery was $254 \pm 78 \min (\min 103, \max 560)$ with a console time of
Table 3 Cases of delayed extubation and duration of post-operative mechanical ventilation

\begin{tabular}{lc}
\hline Case & $\begin{array}{l}\text { Duration of post-operative } \\
\text { mechanical ventilation (min) }\end{array}$ \\
\hline Patient 1 & 190 \\
Patient 2 & 60 \\
Patient 3 & 120 \\
Patient 4 & 415 \\
Patient 5 & 25 \\
Patient 6 & 345 \\
Patient 7 & 135 \\
\hline
\end{tabular}

Table 4 Post-operative events and complications

$\begin{array}{ll}\left.\text { Hypothermia in PACU (temperature }<35^{\circ} \mathrm{C}\right) & 20(15 \%) \\ \text { Mechanical ventilation in PACU (see Table 3) } & 7 / 133(5.3 \%) \\ \text { Nausea and vomiting in PACU } & 11(8.3 \%) \\ \text { Late nausea and vomiting }(24-48 \text { h post-op) } & 2(1.5 \%) \\ \text { Hemorrhage } & 0 \\ \text { Blood transfusion } & 0 \\ \text { Deep-vein thrombosis } & 0 \\ \text { Fever temperature } \geq 38.5^{\circ} \mathrm{C} \text { post-op } & 1 \\ \text { Intra-abdominal abscess } & 1 \\ \text { Post-operative delirium } & 1 \\ \text { Admitted to intensive care unit } & 1 \\ \quad \text { patient with intra-abdominal abscess) } & \\ \text { Deaths related to surgery } & 0 \\ \text { Average hospital stay } & 1.85 \text { days }( \pm 1.4) \\ \text { Median hospital stay } & 1 \text { day }(1-7)\end{array}$

$179 \pm 73 \min (\min 40, \max 516)$. Laparoscopic times prior to docking the robot to the patient were sometimes prolonged by extensive lysis of adhesions and reached $165 \mathrm{~min}$ in one patient with multiple prior laparotomies, although the mean time was 46 min with a standard deviation of $21 \mathrm{~min}$. Post-operative complications are outlined in Table 4. One patient was readmitted with an intra-abdominal abscess which required surgical drainage and admission to the intensive care unit followed by a prolonged hospital stay. The median duration of hospitalization in the study was 1 day with a mean of 1.85 days.

\section{Discussion}

In our case series we looked into the anesthetic considerations, safety and efficiency of robot-assisted gynecologic oncology surgeries in the early learning curves of this procedure in a tertiary care cancer center. The first observation is that robot-assisted gynecologic oncology operations are feasible across a wide range of ages, with $20.3 \%$ of the patients being over the age of 76 . Similarly, the wide range 
of patient BMIs and absence of serious intra-operative complications also suggests that these procedures can be well tolerated in morbidly obese patients $(10.5 \%$ of our patients). Moreover, the brief median post-operative length of hospitalization compares favorably to previously reported hospital stays following laparoscopic and open hysterectomy [5].

Access to the patient is limited, and once the robot has been docked the patient's position cannot be modified rapidly or easily because the robotic arms and platform are locked in a fixed position. Most of the systemic changes in robot-assisted (and other laparoscopic) procedures occur during the creation and maintenance of pneumoperitoneum and are aggravated with steep Trendelenburg positioning. Pneumothorax, pneumomediastinum, and pneumopericardium have been described with laparoscopic surgery and are more likely to occur in patients with diaphragmatic defects and reverse Trendelenburg (e.g. Bochdalek and Morgagni hernias) $[8,9]$. These complications are rare and are usually self-limiting with no adverse hemodynamic consequences. However, subcutaneous emphysema occurs frequently and may contribute significantly to the total amount of $\mathrm{CO}_{2}$ absorbed in addition to the absorption of peritoneal $\mathrm{CO}_{2}$ insufflation [10]. Hyperventilation can usually prevent hypercarbia and respiratory acidosis, but ventilation is often limited during robotic surgery by a higher ventilator inspired pressure with extreme Trendelenburg and abdominal $\mathrm{CO}_{2}$ insufflation, both of which will limit diaphragmatic excursion. Pressure-controlled and volumecontrolled ventilation can both be used during laparoscopic surgery. However, for the same tidal volume, lower peak airway pressure and plateau pressure with higher lung compliance have been observed with the use of pressurecontrolled ventilation in this setting [11] The use of pressure-controlled ventilation may allow a larger tidal volume for the same inspired pressure in patients who are more difficult to ventilate. In patients with high end-tidal $\mathrm{CO}_{2}$ despite optimization of mechanical ventilation settings, permissive hypercarbia can be safely tolerated [12].

The use of positive end-expiratory pressure (PEEP) can decrease atelectasis and has been shown to improve intraoperative oxygenation and lung mechanics [13]. The extreme Trendelenburg positioning could have resulted in atelectasis and significant ventilation-perfusion mismatch but only five patients had one transient (less than $5 \mathrm{~min}$ ) documented episode of hypoxemia with a $\mathrm{SaO}_{2}$ less than 90\% (Table 2). PEEP also impedes venous blood return from the lower extremities and decreases cardiac output, but this effect is mitigated by the extreme Trendelenburg position. The use of PEEP remains controversial in gynecologic robotic surgery because patients are at an increased risk of developing facial, oropharyngeal and laryngeal edema. The use of extreme Trendelenburg and the increased intrathoracic pressure associated with the use of abdominal $\mathrm{CO}_{2}$ insufflation will increase venous congestion in the upper extremity which in turn may cause facial and airway edema. It is therefore important to limit the amount of $\mathrm{CO}_{2}$ insufflation. Despite these concerns, PEEP is routinely used at our institution to minimize atelectasis.

In traditional laparoscopy, pneumoperitoneum is known to cause reduction in lung compliance as well as an immediate transient decrease in cardiac index [14]. Trendelenburg positioning has been associated with increased venous return and cardiac filling pressures. Chest wall compliance will be decreased with cephalad displacement of the diaphragm. These physiologic changes are exaggerated with maximum Trendelenburg positioning but were not associated with major cardiopulmonary adverse events in this study.

In our case series of 133 patients, the occurrence of significant facial and laryngeal edema was rare and was always self-limiting. There was no evidence of brain edema and only seven patients required transient post-operative ventilation in the recovery room (Table 3 ).

Some limitations of this study are inherent to its retrospective nature. First, the exact amount of fluid administered was difficult to quantify for all patients in the chart review process and could have contributed to facial edema. Moreover, the incidence of significant laryngeal edema could have been documented during the management of these cases. A quantitative cuff leak test is an indicator of risk for the development of post-extubation stridor and reintubation [15], but its use was left to the discretion of the anesthesiologist. Third, although pressure-controlled ventilation was frequently used during these procedures, the tidal volume, inspiratory pressure and changes in ventilator parameters during the operation were not consistently documented. In addition, peri-operative subcutaneous emphysema was not documented in patients' charts and this could have affected intra-operative $\mathrm{CO}_{2}$ levels [10]. Lastly, although $\mathrm{CO}_{2}$ insufflation pressure was usually limited to $15 \mathrm{mmHg}$, this was not rigorously controlled and lower insufflation pressures were frequently used. This may have contributed to the low incidence of minor cardiopulmonary complications observed in this case series. Although there are limitations inherent in retrospective analysis, the data presented is reassuring and indicates that despite the risks inherent in fixed docking of the robotic arms, pneumoperitoneum and prolonged maximum Trendelenburg positioning, this procedure has been performed safely in a large number of patients including the elderly and morbidly obese.

Note added in proof The patient with the highest BMI operated on at the time of publication was 68.7 and underwent an uncomplicated hysterectomy, BSO and complete bilateral pelvic lymphadenectomy for endometrial cancer. 
Acknowledgments The authors give special thanks to Claire Deland, Demi Papapanagiotou, the Segal Cancer Centre team, and a group of anonymous philantropists from the Montreal community for their invaluable assistance in the development and implementation of a new robotic surgery program in gynecologic oncology.

Conflict of interest The authors have no commercial or non-commercial affiliations that may be a conflict of interest to disclose. W. Gotlieb has been a proctor for robotics in Canada, China and Israel.

\section{References}

1. Boggess J (2007) Robotic surgery in gynecologic oncology: evolution of a new surgical paradigm. J Robotic Surg 1:31-37

2. Sullivan MJ, Frost EA, Lew MW (2008) Anesthetic care of the patient for robotic surgery. Middle East J Anesthesiol 19(5):967-982

3. Mettler L, Schollmeyer T, Boggess J, Magrina JF, Oleszczuk A (2008) Robotic assistance in gynecological oncology. Curr Opin Oncol 20(5):581-589

4. Kauffman EC, Ng CK, Lee MM, Otto BJ, Portnoff A, Wang GJ, Sherr DS (2009) Critical analysis of complications after roboticassisted radical cystectomy with identification of preoperative and operative risk factors. BJU Int 105(4):520-527

5. Devaja O, Samara I, Papadopoulos AJ (2010) Laparoscopically assisted vaginal hysterectomy (LAVH) versus total abdominal hysterectomy (TAH) in endometrial carcinoma: prospective cohort study. Int J Gynecol Cancer 20(4):570-575

6. Phong SV, Koh LK (2007) Anaesthesia for robotic-assisted radical prostatectomy: considerations for laparoscopy in the Trendelenburg position. Anaesth Intensive Care 35(2):281-285

7. Appledorn SV, Costello AJ (2007) Complications of robotic surgery and how to prevent them. In: Patel VR (ed) Robotic Urologic
Surgery: an introduction and vision for the future. Springer, London, pp 169-178

8. Tanno M, Iizuka T, Fujisawa $\mathrm{K}$, Fukushima H, Watanabe $\mathrm{Y}$ (2009) A case of pneumothorax during laparoscopic surgery due to latent diaphragmatic defect. Masui 58(2):205-208

9. Karayiannakis AJ, Anagnostoulis S, Michailidis K, Vogiatzaki T, Polychronidis A, Simopoulos C (2005) Spontaneous resolution of massive right-sided pneumothorax occurring during laparoscopic cholecystectomy. Surg Laparosc Endosc Percutan Tech 15(2):100-103

10. White P, Recart Freire A (2005) Ambulatory (outpatient) anesthesia. In: Miller RD (ed) Miller's anesthesia, 6th edn. Churchill Livingstone, Philadelphia, pp 2288-2290

11. Ogurlu M, Kucuk M, Bilgin F, Sizlan A, Yanarateş O, Eksert S, Karaşahin E, Coşar A (2010) Pressure-controlled vs volume-controlled ventilation during laparoscopic gynecologic surgery. J Minim Invasive Gynecol 17:295-300

12. Stolzenburg JU, Aedtner B, Olthoff D, Koenig F, Rabenalt R, Filos KS, McNeill A, Liatsikos EN (2006) Anaesthetic considerations for endoscopic extraperitoneal and laparoscopic transperitoneal radical prostatectomy. BJU Int 98(3):508-513

13. Weingarten TN, Whalen FX, Warner DO, Gajic O, Schears GJ, Snyder MR, Schroeder DR, Sprung J (2009) Comparison of two ventilatory strategies in elderly patients undergoing major abdominal surgery. Br J Anaesth 104(1):16-22

14. Wahba RW, Beique F, Kleiman SJ (1995) Cardiopulmonary function and laparoscopic cholecystectomy. Can J Anaesth 42(1):5163

15. Wittekamp BHJ, van Mook WNKA, Tjan DHT, Harm Zwaveling J, Bergmans DCJJ (2009) Clinical review: post-extubation laryngeal edema and extubation failure in critically ill adult patients. Crit Care 13:233 